\title{
Simeprevir and eltrombopag as potential inhibitors of SARS-CoV2 proteases: a molecular docking and virtual screening approach to combat COVID-19
}

Ananta Swargiary ${ }^{* 1}$, Akalesh Kumar Verma ${ }^{2}$, Manita Daimari ${ }^{1}$, Mritunjoy Kumar Roy ${ }^{1}$

${ }^{1}$ Department of Zoology, Bodoland University, Kokrajhar 783370, Assam, India

${ }^{2}$ Department of Zoology, Cotton University, Guwahati 781001, Assam, India

\section{*Address for correspondence}

Dr. Ananta Swargiary

Department of Zoology, Bodoland University, Assam, India

Email: ananbuzoo101@gmail.com

Orchid: https://orcid.org/0000-0001-9594-3666 


\begin{abstract}
Pandemic of COVID-19 has disastrously affected human health and wealth. With no approved drugs until today, the global health system is struggling to find an effective and universal treatment measure. At this crucial juncture, repurposing of existing drugs and medication seems to be the only way out to deal with SARS-CoV2. To find a suitable drug, the present study investigates the binding affinity of 61 selected FDA approved drugs with two key virus proteins, 3-chymotrypsin- and papain-like protease of both SARS-CoV and SARS-CoV2. Furthermore, best binding drugs were investigated for ADMET properties. The 3D structures of SARS-CoV and - CoV2 proteases and drugs were downloaded from PDB and DrugBank databases, respectively. Docking was carried out using AutoDock vina and the output file visualized in Discovery Studio. Druglikeness and toxicity were studied using SwissADME and ADMETlab. Simeprevir $(-9.4 \mathrm{kcal} / \mathrm{mol})$ and eltrombopag $(-9.3 \mathrm{kcal} / \mathrm{mol})$ were found to be the best 3CLpro binding drugs in SARS-CoV2 and SARS-CoV, respectively. Similarly, eltrombopag showed the best affinity to PLpro in both the viruses. The average docking score of 61 drugs with 3CLpro and PLpro was found to be -7.19 and $-6.56 \mathrm{kcal} / \mathrm{mol}$ in SARS-CoV2 and -7.11 and -7.06 $\mathrm{kcal} / \mathrm{mol}$ in SARS-CoV, respectively. ADMET study of the top ten drugs revealed that most of the drugs are highly absorbed by the human intestine and pass through the blood-brain barrier and distribute easily. Furthermore, most of the drugs including simeprevir, saquinavir, and vaniprevir were found to act as strong inhibitors of CYP-enzyme complex which therefore cannot metabolize the drugs before reaching the target site. In-silico toxicity study did not show any carcinogenic property of the top ten drugs. The findings of the present study, thus suggests that the use of existing antiviral drugs as well as unknown antiviral drugs such as eltrombopag, digoxin may prove effective against SARS-CoV2.
\end{abstract}

Keywords: Simeprevir; Eltrombopag; COVID-19; SARS-CoV2; Proteases; Docking, ADMET 


\section{Introduction}

Coronaviruses (CoV) are a group of positive-sense, single-stranded RNA (ssRNA) viruses belonging to the sub-family Coronavirinae, family Coronaviridae, and order Nidovirales. Viruses belonging to this group possess crown-like protein spikes on the outer surface of the virus-coat and hence named as 'coronavirus'. There are four sub-groups of CoV - Alpha-, Beta-, Gamma-, and Delta-coronaviruses, and the size ranges from $65-125 \mathrm{~nm}$ diameters and the genome size $26-32 \mathrm{~kb}$ ssRNA. Till today there are four known human coronaviruses (HCoV) - HCoV-229E, -OC43, -NL63, and -HKU1 that are known to cause mild infections such as common cold in immunocompetent individuals while two highly pathogenic CoVs - Severe Acute Respiratory Syndrome coronavirus (SARS-CoV) and Middle East Respiratory Syndrome coronavirus (MERS-CoV) induces severe respiratory complications in humans (Su et al., 2016; Cui et al., 2019). Based on sequence homology studies it is known that all the human CoVs have originated from bats while HKU1 and HCoV-OC43 are linked to rodents (Forni et al., 2017). SARS-CoV2 is a new coronavirus that emerged in late 2019 from Wuhan city of China in the form of a global pandemic disease called COVID-19 (Benvenuto et al., 2020). Like SARS and MERS, SARS$\mathrm{CoV} 2$ is also a highly contagious and pathogenic coronavirus that causes severe respiratory problems and even death. Genomic studies have found that SARS-CoV2 is phylogenetically close to other SARS-like coronaviruses (Wu et al., 2020). Till today COVID-19 has invaded almost the entire world affecting more than 17.7 million of people and more than 700 thousands death worldwide (WHO). The attack and pathogenicity of SARS-CoV2 start at the lower respiratory system followed by invasion of pulmonary epithelial cells and hijacks the host cell machinery. The most common symptoms of COVID-19 include cough, fever, malaise, gastrointestinal symptoms, loss of smell, and sore throat (Gandhi et al., 2020).

At present, there is no clinically approved drug or vaccine against COVID-19. However, attempts have been made to reduce the virus load and improve the symptoms by using known antiviral drugs and related clinical practices (McKee et al., 2020). Researchers around the world are working diligently to develop effective drugs based on the pathogenicity and molecular details of the SARS CoV-2 and related coronaviruses. One of the major therapeutic drug targets of human $\mathrm{CoVs}$ is to inhibit the functioning of two protease enzymes - 3 Chymotrypsin-like proteases (3CLpro), also known as main protease (Mpro), and Papain-like protease (PLpro) (Li et al., 2020; Zhou et al., 2020). Encoded by Open Reading Frame-1 (ORF-1) of viral genome 3CLpro and PLpro enzymes play a major role in the processing of polyproteins (pp1a and pp1ab) into active non-structural proteins (nsp). These nsps are known to be involved in the transcription and replication of viral genome (Hilgenfeld, 2014; Dai et al., 2020). 3CLpro and PLpro are also known to have crucial role in virus infection, assembly, and generation (Ma-Lauer et al., 2016; Zhou et al., 2019). There two protease enzymes, 3CLpro and PLpro, are therefore considered to be a promising candidate for therapeutic drug target (Wu et al., 2020). Recent studies have demonstrated that the two protease enzyme 3CLpro and PLpro of SARS-CoV share about $96 \%$ and $83 \%$ sequence identity with SARS-CoV2 at the protein level (Morse et al., 2020). Similarly, crystallographic and molecular modeling studies have also revealed that despite its differences of 
amino acid sequences in the 3CL and PL proteases of SARS-CoV and - CoV-2, there are striking similarities in the ligand-binding sites of the enzymes (Macchiagodena et al., 2020; Shin et al., 2020). In that perspective, candidate drugs that are used for SARS-CoV may also be tested for its effectiveness against novel coronavirus SARS-CoV2. The molecular docking is a common, widely used in-silico technique that assesses the binding affinity between ligand and protein and can be used to design novel inhibitors against disease-causing biological targets (Bhattacharyya et al., 2019). Using this method virtual screening of a large number of chemicals can be made to select the lead compounds of probable drug candidates (Huang and Zou, 2010; Swargiary et al., 2020). At this time of COVID-19 pandemic, it is of utmost importance to look for speedy alternatives so that the raising spread of SARS-CoV2 can be managed. In an attempt to combat COVID-19, the present study investigates the binding affinities of FDA recommended drugs on 3CL protease and PL proteases of SARS-CoV2 and compared the result with SARS-CoV. Furthermore, we also studied the in-silico ADMET properties of the selected drugs.

\section{Materials and Methods}

\subsection{Ligand Selection and Preparation}

A total of 61 FDA recommended COVID-19 drugs were taken from DrugBank database (https://www.drugbank.ca/). The PDB files of the ligands were processed and finally converted into .pdbqt file using AutoDock tool (Trott and Olson, 2010).

\subsection{Collection and Preparation of Proteins}

Three-dimensional structures of 3CL proteases of SARS-CoV (PDB ID: 4TWY) and SARSCoV2 (PDB ID: 7BUY) and PL Proteases of SARS-CoV (PDB ID: 3MJ5) and SARS-CoV2 (PDB ID: 6XAA) were downloaded from PDB database. The protein structures were cleaned by removing the water and other hetatms. Polar hydrogens and Kollman charges were added to the structure and finally converted into .pdbqt format for docking using AutoDock Tools.

\subsection{Sequence alignment and Superimposition}

The amino acid sequence of both the proteins for SARS-CoV and $-\mathrm{CoV}-2$ was collected from the PDB database. Multiple sequence alignment was carried out in ClustalW (https://www.genome.jp/tools-bin/clustalw). Superimpositions of the cleaned protein structures were performed in the Chimera tool (Pettersen et al., 2004).

\subsection{Molecular Docking}

After the ligands and the target enzymes were prepared docking was carried out in AutoDock Vina (Trott and Olson, 2010). The active pocket amino acids selected for 3CLpro were Thr-45, Met-49, Phe-140, Asn-142, Asp-187, Arg-188, Gln-189, Met-165, His-172, Glu-166 including the catalytic dyad His-41, Cys-145. Similarly, for PLpro the amino acids were Leu-163, Gly-164, Asp-165, Pro-248, Pro-249, Tyr-269, Gln-270, Tyr-274, and Thr-302 including the catalytic triad, Cys-112-His-273-Asp-287. The grid parameters were set as $\mathrm{x}, \mathrm{y}, \mathrm{z}$ size-coordinate and 
grid box centre-coordinate: 46, 46, 66 and -13.137, 14.854, 69.809 for 3CLpro for SARS-CoV2, and 58, 52, 64 and $-37.547,22.916$, and -9.733 for SARS-CoV2 PLpro. Similarly, for SARS$\mathrm{CoV}$ proteases, the grid parameters were set as $\mathrm{x}, \mathrm{y}, \mathrm{z}$ size-coordinate and grid box centrecoordinate: $66,46,52$, and $-23.761,-42.344$, and 5.092 for 3CLpro and 48, 64, 46, and -17.489, 51.252 and -39.421 for PLpro, respectively. The docking algorithm was carried out by keeping the default exhaustiveness at 8. After docking, the pose scoring the lowest binding energy (binding affinity in $\mathrm{kcal} / \mathrm{mol}$ ) was selected and visualize in Discovery Studio.

\subsection{Validation based on machine learning algorithms}

Bayesian machine learning models from Assay Central platform (https:/assaycentral.github.io/\#) was used to determine the applicability score for potent compounds (based on docking score) that could function against SARS-CoV2. Assay Central is a method for the development of machine learning models (Bayesian, Random Forest, and Deep Neural Networks, etc.) that can be used ultimately to filter and score target-specific lead compounds prior to wet laboratory validation (Clark et al., 2015). It is a collection of predictive Bayesian and Random Forest (RF) models in a self-contained executable for non-experts to evaluate the likelihood of activity against target of interest. The output includes a prediction score $(\mathrm{Pm})$ and applicability score (AS) (percentage of molecular fragments present in the model input). The Pm is the summation of fingerprint $i$ and contributions, $\mathrm{C} i$. Contribution is based on the number of active compounds with the fingerprint, $\mathrm{Ai}$, out of the total compounds with the fingerprint, $\mathrm{Ti}$, and the total number of active compounds in the dataset, R (Clark et al., 2015; Krems, 2019).

$$
\begin{gathered}
\mathrm{C} i=\log \frac{A i+1}{T i R+1} \\
\mathrm{Pm}=\sum_{i}^{F} \mathrm{C} i
\end{gathered}
$$

\subsection{Analysis of druglikeness and ADMET properties}

Top ten docking score drugs and the druglikeness properties were studied using SwissADME (Daina et al., 2017) and PubChem database (https://pubchem.ncbi.nlm.nih.gov/). The absorption, distribution, metabolism, excretion, and toxicity (ADMET) properties of drugs were predicted using online database, ADMETlab (Dong et al., 2018).

\section{Results}

\subsection{Sequence alignment and superimposition}

Multiple sequence alignment and 3D structure superimposition between SARS-CoV and-CoV-2 protease enzymes, 3CLpro, and PLpro is shown in Fig. 1. The protease enzyme 3CLpro consists of 306 amino acid residues in both the viruses. Sequence comparison studies have shown that SARS-CoV and CoV-2 share $95.72 \%$ sequence identity in the main protease enzyme 3CLpro 
(Fig 1a). The main protease showed differences in 13 amino acid residues between the two viruses out of which 6 are having similar properties. The superimposition of the 3D structure of the enzymes showed that the two structures have a root mean square deviation (RMSD) $0.641 \AA$ (Fig 1c). Most of the deviations were observed in the coil region of the protein structures. On the contrary, PLpro of two viruses has $82.85 \%$ sequence identity. A total of 53 amino acids were found to differ between the two structures out of which 15 residues are similar in nature (Fig $1 \mathrm{~b}$ ). The RMSD between the two structures is found to be $1.008 \AA$ (Fig 1d).
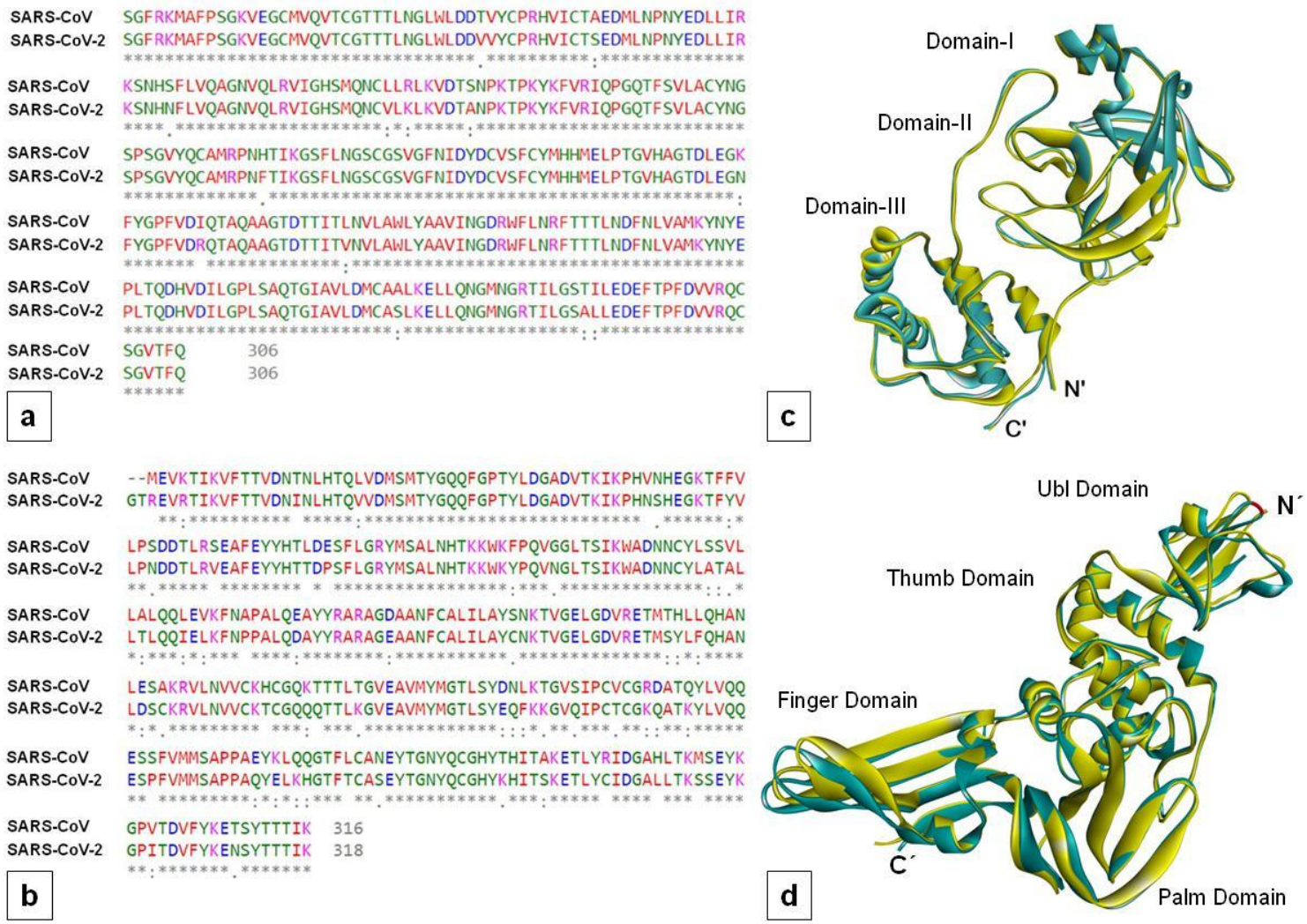

Fig. 1 Multiple sequence alignment and superimposition of 3-Chymotrypsin-like and Papain-like proteases of SARS-CoV (yellow) and SARS-CoV2 (cyan). Multiple sequence alignment of 3CLpro (a) and PLpro (b) and Superimposition of 3 C-like proteases (c), and P-like proteases (d). Ubl - N-terminal ubiquitin-like domain.

\subsection{Molecular Docking Studies}

Docking studies were carried out with a total of 61 FDA recommended COVID-19 drugs and are screened for binding affinity to the active sites of two key therapeutic drug target proteins, 3CLpro and PLpro. Among these drugs, 18 compounds are known protease inhibitors while the others include antimalarial, antiviral, antibacterial, antihelmintic, antitumor, etc (Table 1). The docking score of all the drugs against 3CLpro and PLpro of both CoVs are presented in Fig. 2. It is seen from the study that the drugs showed marked variations in the binding affinities. Most of 
the drugs showed a better binding affinity to SARS-CoV 3CLpro enzyme compared to SARSCoV2. However, the range of binding energies is almost the same in both the CoVs. The binding energies of drugs ranged from -4.8 to $-9.4 \mathrm{kcal} / \mathrm{mol}$ in 3CLpro of SARS-CoV2, while in the case of SARS-CoV, the binding energy ranged from -5.9 to $-9.3 \mathrm{kcal} / \mathrm{mol}$. Protease inhibitor simeprevir showed best binding affinity $(-9.4 \mathrm{kcal} / \mathrm{mol})$ with 3CLpro of SARS-CoV2 while, eltrombopag, a drug used for the treatment of thrombocytopenia is found to have best binding affinity $(-9.3 \mathrm{kcal} / \mathrm{mol})$ with 3CLpro of SARS-CoV. The binding affinity of simeprevir is followed by digoxin, vaniprevir, saquinavir, ivermectin, and finally fingolimod in 3CLpro of SARS-CoV2. Similarly, in case of SARS-CoV, eltrombopag is followed by digoxin, ciclesonide, saquinavir, abemaciclib, and finally favipiravir (Fig. 2a). On the contrary, Eltrombopag showed highest binding affinity with the PLpro of both SARS-CoV (-9.1 kcal/mol) and -CoV-2 (kcal/mol) (Fig 2b). Eltrombopag is followed by simeprevir, digoxin, losartan, and finally chloroquine in SARS-CoV2 PLpro while in the case of SARS-CoV, eltrombopag is followed by abemaciclib, penfluridol, bazedoxifene, and finally chloroquine.

Table 1 - A list of 61 FDA approved drugs recommended for COVID-19 (Clercq and Li, 2016; Jeon et al., 2020).

\begin{tabular}{|c|c|c|c|c|c|c|}
\hline Sl. no. & Name & Mol. mass & Mol. formula & DB-ID & Target & $\begin{array}{l}\text { *FDA } \\
\text { status }\end{array}$ \\
\hline 1. & Abemaciclib & 506.606 & $\mathrm{C}_{27} \mathrm{H}_{32} \mathrm{~F}_{2} \mathrm{~N}_{8}$ & DB12001 & antitumour & App \\
\hline 2. & Amodiaquine & 355.861 & $\mathrm{C}_{20} \mathrm{H}_{22} \mathrm{ClN}_{3} \mathrm{O}$ & DB00613 & antimalarial & App \\
\hline 3. & Amprenavir & 505.627 & $\mathrm{C}_{25} \mathrm{H}_{35} \mathrm{~N}_{3} \mathrm{O}_{6} \mathrm{~S}$ & DB00701 & protease inhibitor & App \\
\hline 4. & Anidulafungin & 1140.24 & $\mathrm{C}_{58} \mathrm{H}_{73} \mathrm{~N}_{7} \mathrm{O}_{17}$ & DB00362 & anti-fungal & App \\
\hline 5. & Asunaprevir & 748.286 & $\mathrm{C}_{35} \mathrm{H}_{46} \mathrm{ClN}_{5} \mathrm{O}_{9} \mathrm{~S}$ & DB11586 & protease inhibitor & App \\
\hline 6. & Atazanavir & 704.8555 & $\mathrm{C}_{38} \mathrm{H}_{52} \mathrm{~N}_{6} \mathrm{O}_{7}$ & DB01072 & protease inhibitor & App \\
\hline 7. & Bazedoxifene & 470.613 & $\mathrm{C}_{30} \mathrm{H}_{34} \mathrm{~N}_{2} \mathrm{O}_{3}$ & DB06401 & $\begin{array}{l}\text { estrogen receptor } \\
\text { modulator }\end{array}$ & App \\
\hline 8. & berberine & 336.3612 & $\mathrm{C}_{20} \mathrm{H}_{18} \mathrm{NO}_{4}$ & DB04115 & anti-parasite & App \\
\hline 9. & Boceprevir & 519.6767 & $\mathrm{C}_{27} \mathrm{H}_{45} \mathrm{~N}_{5} \mathrm{O}_{5}$ & DB08873 & protease inhibitor & App \\
\hline 10. & Camostat & 398.4125 & $\mathrm{C}_{20} \mathrm{H}_{22} \mathrm{~N}_{4} \mathrm{O}_{5}$ & DB13729 & protease inhibitor & Exp \\
\hline 11. & Chloroquine & 319.872 & $\mathrm{C}_{18} \mathrm{H}_{26} \mathrm{ClN}_{3}$ & DB00608 & antimalarial & App \\
\hline 12. & Ciclesonide & 540.697 & $\mathrm{C}_{32} \mathrm{H}_{44} \mathrm{O}_{7}$ & DB01410 & $\begin{array}{l}\text { obstructive airway } \\
\text { diseases }\end{array}$ & App \\
\hline 13. & Clomifene & 405.96 & $\mathrm{C}_{26} \mathrm{H}_{28} \mathrm{ClNO}$ & DB00882 & $\begin{array}{l}\text { estrogen agonist / } \\
\text { antagonist }\end{array}$ & App \\
\hline 14. & Cyclosporine & 1202.635 & $\mathrm{C}_{62} \mathrm{H}_{111} \mathrm{~N}_{11} \mathrm{O}_{12}$ & DB00091 & $\begin{array}{l}\text { immunomodulator } \\
\mathrm{y}\end{array}$ & App \\
\hline 15. & Danoprevir & 731.84 & $\mathrm{C}_{35} \mathrm{H}_{46} \mathrm{FN}_{5} \mathrm{O}_{9} \mathrm{~S}$ & DB11779 & protease inhibitor & App \\
\hline 16. & Darunavir & 547.664 & $\mathrm{C}_{27} \mathrm{H}_{37} \mathrm{~N}_{3} \mathrm{O}_{7} \mathrm{~S}$ & DB01264 & protease inhibitor & App \\
\hline 17. & Digoxin & 780.9385 & $\mathrm{C}_{41} \mathrm{H}_{64} \mathrm{O}_{14}$ & DB00390 & $\begin{array}{l}\text { cardiovascular } \\
\text { medications }\end{array}$ & App \\
\hline 18. & Dronedarone & 556.756 & $\mathrm{C}_{31} \mathrm{H}_{44} \mathrm{~N}_{2} \mathrm{O}_{5} \mathrm{~S}$ & DB04855 & antiarrhythmic & App \\
\hline 19. & Ebastine & 469.6576 & $\mathrm{C}_{32} \mathrm{H}_{39} \mathrm{NO}_{2}$ & DB11742 & $\begin{array}{l}\text { irritable bowel } \\
\text { syndrome }\end{array}$ & App \\
\hline 20. & Eltrombopag & 442.4666 & $\mathrm{C}_{25} \mathrm{H}_{22} \mathrm{~N}_{4} \mathrm{O}_{4}$ & DB06210 & $\begin{array}{l}\text { treat low blood } \\
\text { platelet counts }\end{array}$ & App \\
\hline 21. & Favipiravir & 157.104 & $\mathrm{C}_{5} \mathrm{H}_{4} \mathrm{FN}_{3} \mathrm{O}_{2}$ & DB12466 & influenza & App \\
\hline 22. & Fingolimod & 307.4708 & $\mathrm{C}_{19} \mathrm{H}_{33} \mathrm{NO}_{2}$ & DB08868 & anti-sclerosis & App \\
\hline
\end{tabular}




\begin{tabular}{|c|c|c|c|c|c|c|}
\hline 23. & Fosamprenavir & 585.607 & $\mathrm{C}_{25} \mathrm{H}_{36} \mathrm{~N}_{3} \mathrm{O}_{9} \mathrm{PS}$ & DB01319 & protease inhibitor & App \\
\hline 24. & Gilteritinib & 552.724 & $\mathrm{C}_{29} \mathrm{H}_{44} \mathrm{~N}_{8} \mathrm{O}_{3}$ & DB12141 & $\begin{array}{l}\text { tyrosine kinase } \\
\text { inhibitors }\end{array}$ & App \\
\hline 25. & Grazoprevir & 766.903 & $\mathrm{C}_{38} \mathrm{H}_{50} \mathrm{~N}_{6} \mathrm{O}_{9} \mathrm{~S}$ & DB11575 & protease inhibitor & App \\
\hline 26. & Hexachlorophene & 406.904 & $\mathrm{C}_{13} \mathrm{H}_{6} \mathrm{Cl}_{6} \mathrm{O}_{2}$ & DB00756 & antibacterial & App \\
\hline 27. & $\begin{array}{l}\text { Hydroxychloroquin } \\
\mathrm{e}\end{array}$ & 335.872 & $\mathrm{C}_{18} \mathrm{H}_{26} \mathrm{ClN}_{3} \mathrm{O}$ & DB01611 & antimalarial & App \\
\hline 28. & $\begin{array}{l}\text { Hydroxyprogestero } \\
\text { ne }\end{array}$ & 428.6041 & $\mathrm{C}_{27} \mathrm{H}_{40} \mathrm{O}_{4}$ & DB06789 & $\begin{array}{l}\text { prevention of } \\
\text { spontaneous } \\
\text { preterm births }\end{array}$ & App \\
\hline 29. & Indinavir & 613.7895 & $\mathrm{C}_{36} \mathrm{H}_{47} \mathrm{~N}_{5} \mathrm{O}_{4}$ & DB00224 & protease inhibitor & App \\
\hline 30. & Ivacaftor & 392.4907 & $\mathrm{C}_{24} \mathrm{H}_{28} \mathrm{~N}_{2} \mathrm{O}_{3}$ & DB08820 & cystic fibrosis & App \\
\hline 31. & Ivermectin & 1736.1589 & $\mathrm{C}_{95} \mathrm{H}_{146} \mathrm{O}_{28}$ & DB00602 & anti-parasitic & App \\
\hline 32. & Loperamide & 477.038 & $\mathrm{C}_{29} \mathrm{H}_{33} \mathrm{ClN}_{2} \mathrm{O}_{2}$ & DB00836 & antidiarrheals & App \\
\hline 33. & Lopinavir & 628.800 & $\mathrm{C}_{37} \mathrm{H}_{48} \mathrm{~N}_{4} \mathrm{O}_{5}$ & DB01601 & protease inhibitor & App \\
\hline 34. & Losartan & 422.911 & $\mathrm{C}_{22} \mathrm{H}_{23} \mathrm{ClN}_{6} \mathrm{O}$ & DB00678 & ACE- inhibitors & App \\
\hline 35. & Lusutrombopag & 591.54 & $\mathrm{C}_{29} \mathrm{H}_{32} \mathrm{Cl}_{2} \mathrm{~N}_{2} \mathrm{O}_{5} \mathrm{~S}$ & DB13125 & $\begin{array}{l}\text { thrombopoietin } \\
\text { receptor agonist }\end{array}$ & App \\
\hline 36. & Mefloquine & 378.3122 & $\mathrm{C}_{17} \mathrm{H}_{16} \mathrm{~F}_{6} \mathrm{~N}_{2} \mathrm{O}$ & DB00358 & antimalarials & App \\
\hline 37. & Mequitazine & 322.467 & $\mathrm{C}_{20} \mathrm{H}_{22} \mathrm{~N}_{2} \mathrm{~S}$ & DB01071 & antihistamine & App \\
\hline 38. & $\begin{array}{l}\text { Methylprednisolon } \\
\text { e }\end{array}$ & 374.4706 & $\mathrm{C}_{22} \mathrm{H}_{30} \mathrm{O}_{5}$ & DB00959 & $\begin{array}{l}\text { coronavirus } \\
\text { pneumonia }\end{array}$ & App \\
\hline 39. & Nelfinavir & 567.782 & $\mathrm{C}_{32} \mathrm{H}_{45} \mathrm{~N}_{3} \mathrm{O}_{4} \mathrm{~S}$ & DB00220 & protease inhibitor & App \\
\hline 40. & Niclosamide & 327.12 & $\mathrm{C}_{13} \mathrm{H}_{8} \mathrm{Cl}_{2} \mathrm{~N}_{2} \mathrm{O}_{4}$ & DB06803 & antihelmintic & App \\
\hline 41. & Oseltamivir & 312.4045 & $\mathrm{C}_{16} \mathrm{H}_{28} \mathrm{~N}_{2} \mathrm{O}_{4}$ & DB00198 & antiviral & App \\
\hline 42. & Osimertinib & 499.619 & $\mathrm{C}_{28} \mathrm{H}_{33} \mathrm{~N}_{7} \mathrm{O}_{2}$ & DB09330 & $\begin{array}{l}\text { tyrosine kinase } \\
\text { inhibitor }\end{array}$ & App \\
\hline 43. & Ouabain & 584.6525 & $\mathrm{C}_{29} \mathrm{H}_{44} \mathrm{O}_{12}$ & DB01092 & $\begin{array}{l}\text { inhibitor of } \mathrm{Na} / \mathrm{K}- \\
\text { ATPase }\end{array}$ & App \\
\hline 44. & Penfluridol & 523.97 & $\mathrm{C}_{28} \mathrm{H}_{27} \mathrm{ClF}_{5} \mathrm{NO}$ & DB13791 & antipsychotic & Exp \\
\hline 45. & Perhexiline & 277.4879 & $\mathrm{C}_{19} \mathrm{H}_{35} \mathrm{~N}$ & DB01074 & $\begin{array}{l}\text { CPT-1 \& CPT-2 } \\
\text { inhibitor }\end{array}$ & App \\
\hline 46. & Phenazopyridine & 213.2385 & $\mathrm{C}_{11} \mathrm{H}_{11} \mathrm{~N}_{5}$ & DB01438 & $\begin{array}{l}\text { urinary tract } \\
\text { irritation }\end{array}$ & App \\
\hline 47. & Pirfenidone & 185.2218 & $\mathrm{C}_{12} \mathrm{H}_{11} \mathrm{NO}$ & DB04951 & $\begin{array}{l}\text { multiple fibrotic } \\
\text { conditions }\end{array}$ & App \\
\hline 48. & Proscillaridin & 530.658 & $\mathrm{C}_{30} \mathrm{H}_{42} \mathrm{O}_{8}$ & DB13307 & anticancer & Exp \\
\hline 49. & Quinacrine & 399.957 & $\mathrm{C}_{23} \mathrm{H}_{30} \mathrm{ClN}_{3} \mathrm{O}$ & DB01103 & antimalarial & Inv \\
\hline 50. & Remdesivir & 602.585 & $\mathrm{C}_{27} \mathrm{H}_{35} \mathrm{~N}_{6} \mathrm{O}_{8} \mathrm{P}$ & DB14761 & $\begin{array}{l}\text { potential treatment } \\
\text { for Ebola }\end{array}$ & Inv \\
\hline 51. & Ritonavir & 720.944 & $\mathrm{C}_{37} \mathrm{H}_{48} \mathrm{~N}_{6} \mathrm{O}_{5} \mathrm{~S}_{2}$ & DB00503 & protease inhibitor & App \\
\hline 52. & Salinomycin & 751.011 & $\mathrm{C}_{42} \mathrm{H}_{70} \mathrm{O}_{11}$ & DB11544 & $\begin{array}{l}\text { inhibitor of wnt } / \beta \text { - } \\
\text { catenin signaling }\end{array}$ & Vet. App \\
\hline 53. & Saquinavir & 670.8408 & $\mathrm{C}_{38} \mathrm{H}_{50} \mathrm{~N}_{6} \mathrm{O}_{5}$ & DB01232 & protease inhibitor & App \\
\hline 54. & Sildenafil & 474.576 & $\mathrm{C}_{22} \mathrm{H}_{30} \mathrm{~N}_{6} \mathrm{O}_{4} \mathrm{~S}$ & DB00203 & $\begin{array}{l}\text { CGMP specific } \\
\text { phosphodiesterase }\end{array}$ & App \\
\hline 55. & Simeprevir & 749.939 & $\mathrm{C}_{38} \mathrm{H}_{47} \mathrm{~N}_{5} \mathrm{O}_{7} \mathrm{~S}_{2}$ & DB06290 & $\begin{array}{l}\text { pype } 5 \text { innibitor } \\
\text { protease inhibitor }\end{array}$ & App \\
\hline 56. & Telaprevir & 679.8493 & $\mathrm{C}_{36} \mathrm{H}_{53} \mathrm{~N}_{7} \mathrm{O}_{6}$ & DB05521 & protease inhibitor & App \\
\hline 57. & Thalidomide & 258.2295 & $\mathrm{C}_{13} \mathrm{H}_{10} \mathrm{~N}_{2} \mathrm{O}_{4}$ & DB01041 & immunosuppresive & App \\
\hline 58. & Thioridazine & 370.575 & $\mathrm{C}_{21} \mathrm{H}_{26} \mathrm{~N}_{2} \mathrm{~S}_{2}$ & DB00679 & $\begin{array}{l}\text { psychoses, } \\
\text { schizophrenia }\end{array}$ & App \\
\hline 59. & Tipranavir & 602.664 & $\mathrm{C}_{31} \mathrm{H}_{33} \mathrm{~F}_{3} \mathrm{~N}_{2} \mathrm{O}_{5} \mathrm{~S}$ & DB00932 & protease inhibitor & App \\
\hline
\end{tabular}



60. Toremifene
405.96
$\mathrm{C}_{26} \mathrm{H}_{28} \mathrm{ClNO}$
DB00539
estrogen receptor
App
61. Vaniprevir
757.936
$\mathrm{C}_{38} \mathrm{H}_{55} \mathrm{~N}_{5} \mathrm{O}_{9} \mathrm{~S}$
DB11929
dulator
protease inhibitor
Inv

DB-Drugbank, App- approved, Exp - Experimental, Vet- veterinary, Inv - investigational, *FDA status https://go.drugbank.com/

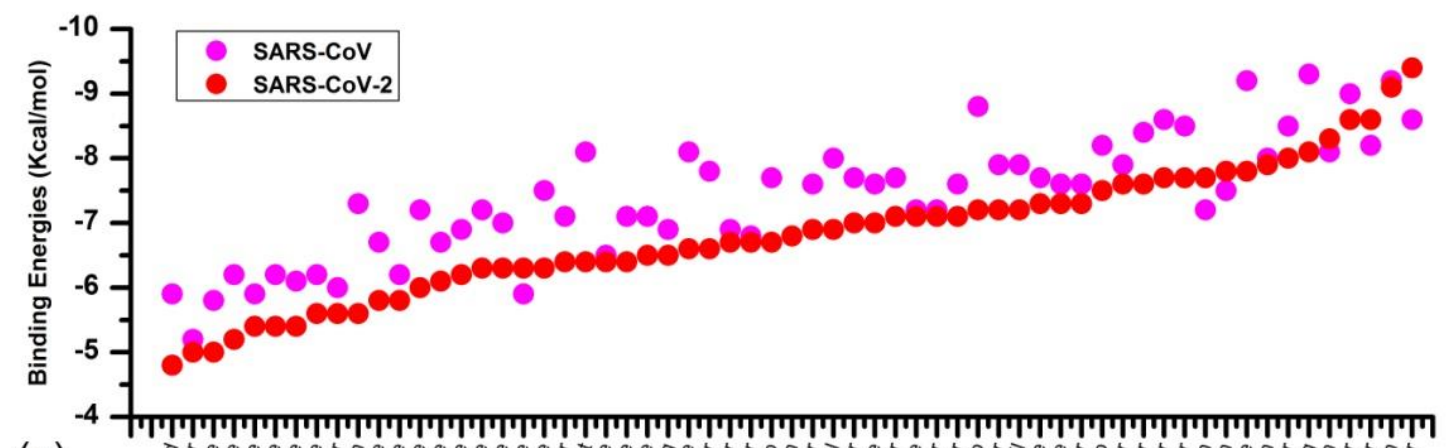

(a)

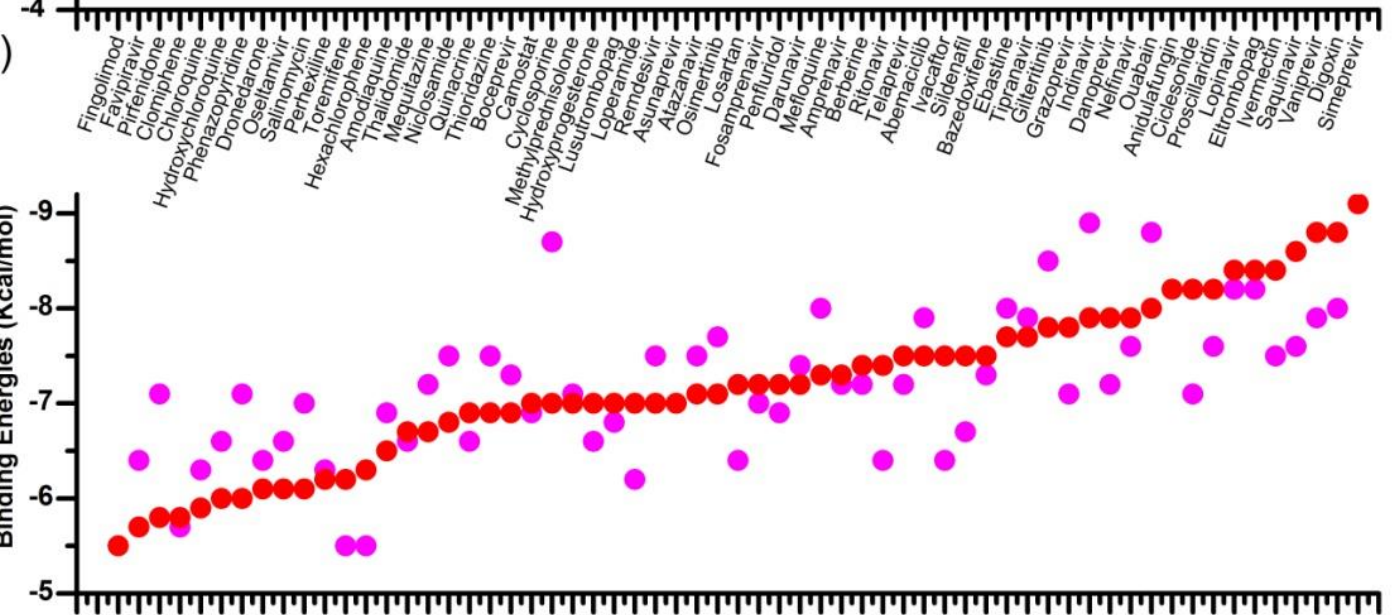

(b)

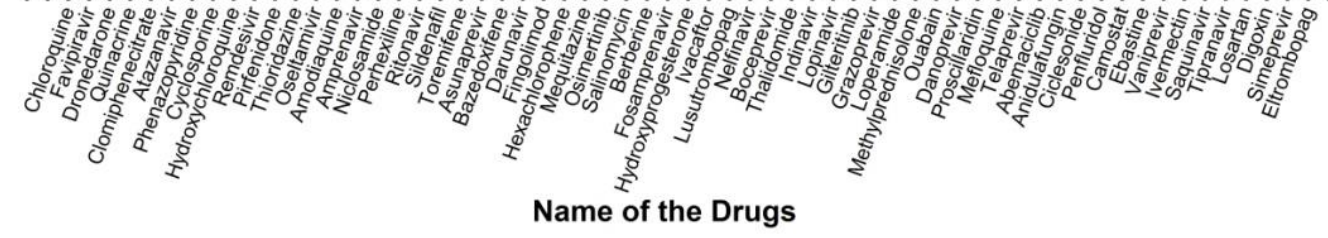

Fig. 2 Docking score of different drugs with (a) 3-chymotrypsin-like protease enzyme of SARS-CoV and SARS CoV-2, and (b) Papain-like protease enzyme of SARS-CoV and SARS CoV-2

Fig. 3a showed the ligand-binding site sphere view simeprevir and 3CLpro of SARS-CoV2. Binding studies showed that a total of 16 amino acids (Lys-5, Arg-131, Lys-137, Thr-169, Val171, Ala-194, Thr-196, Asp-197, Thr-199, Tyr-237, Asn-238, Tyr-239, Leu-287, Glu-288, Asp289, and Glu-290) of 3CLpro were found to have interaction with the simeprevir. Two amino acids, Asn238 and Asp389 made three hydrogen bonds with simeprevir having 2.332 and $2.474 \AA$ bond lengths (Fig. 3b). Amino acid Lys-137 is found to have favorable affinity of making H-bond with simeprevir. The other interactions involved Van der Waals interactions, 
carbon-hydrogen $(\mathrm{C}-\mathrm{H})$ bond, and alkyl bonds. Fig 3d \& 3e showed the H-bond donor (HBD) and acceptor (HBA) as well as hydrophobicity of ligand-surrounding amino acids. Among the $3 \mathrm{H}$-bonds, simeprevir acts as 1HBD and 2HBA with 3CLpro. The hydrophobicity surface view revealed that out of 16 amino acid residues surrounding the ligand, 14 residues showed hydrophilic property while two amino acids, Val-171 and Leu-287 were hydrophobic in nature (Fig 3e). Fig. 3c \& 3f showed the Ramachandran plot of complete 3CLpro structure and ligand surrounding amino acid residues, respectively. Three amino acids, Gly-2, -143, and -275 found in the turn and coil region of 3CLpro were found to lie in disallowed regions. Furthermore, all the 16 amino acids surrounding simeprevir were in the allowed regions that are involved in $\beta$ sheet structure of the enzyme (Fig. 3f).
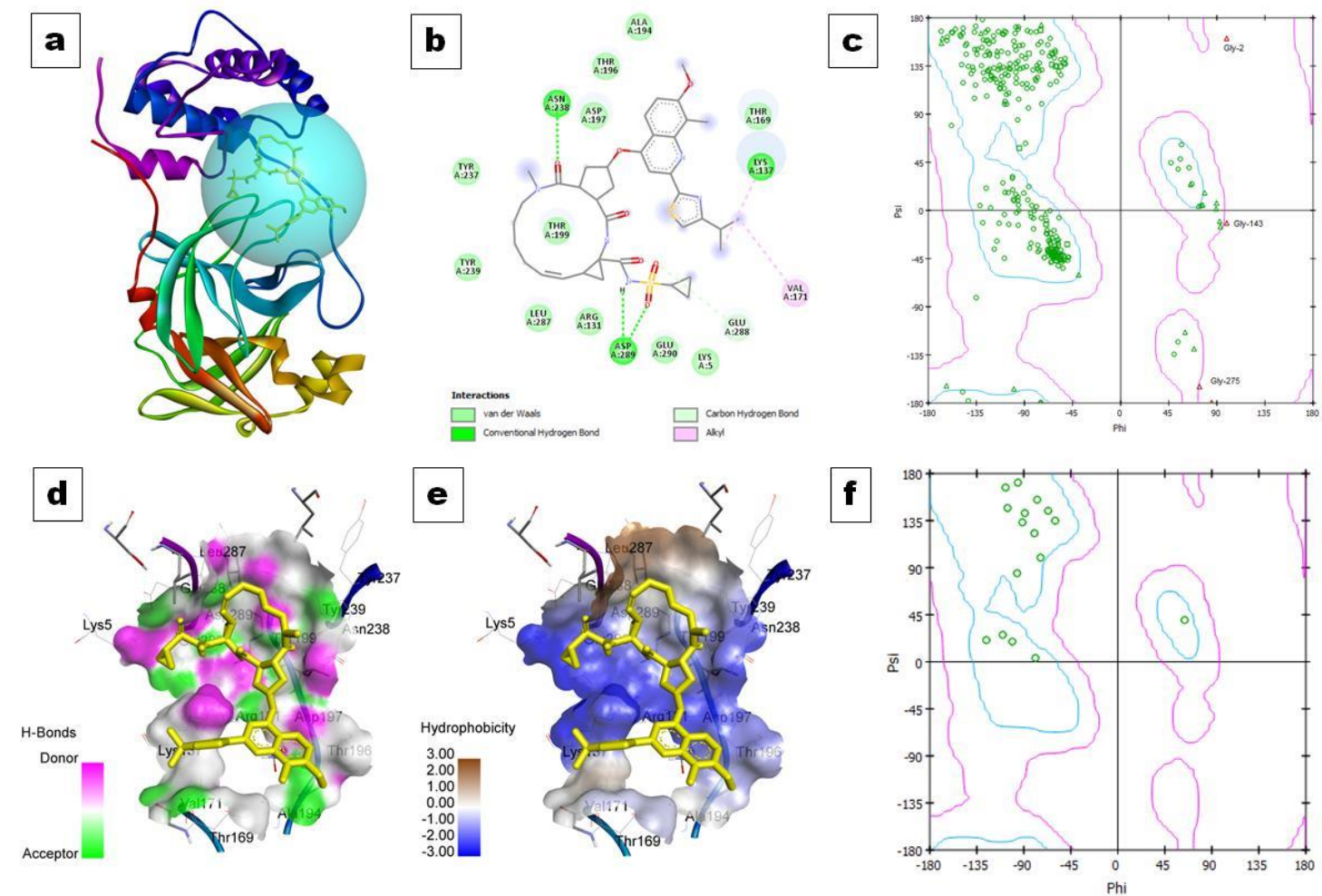

Fig. 3 Binding interactions of SARS-CoV2 3CLpro and simeprevir. (a) Ligand binding sphere view of 3CLpro, (b) 2D display of simeprevir-3CLpro interactions, (c) Ramachandran plot of 3CLpro, (d) H-bond property of binding pocket, (e) Hydrophobicity profile of binding pocket, and (f) Ramachandran plot of simeprevir interacting amino acid residues.

In comparison to SARS-CoV2, SARS-CoV 3CLpro showed a slightly different ligand binding pattern. Fig 4(a-f) showed the nature of binding interactions between SARS-CoV 3CLpro and eltrombopag. Fig 4a showed a slightly different ligand binding site in 3CLpro of SARS-CoV. A total of 12 amino acid residues were found to make interactions between 3CLpro and eltrombopag (Fig. 4b). Three amino acid residues, Gln-110, Thr-111, and Thr-292 were found to make three conventional H-bondings with the ligand. Other non-covalent bondings such 
as Van der Waal's interactions (4 amino acids), pi-bonds, etc were also observed between protein-ligand complexes. Fig $3 \mathrm{~d} \& 3 \mathrm{e}$ showed the HBD and HBA amino acids and hydrophobicity of the ligand surrounding amino acids. Out of 15 ligand surrounding amino acid residues, 8 were found to have strong hydrophilicity. The Ramachandran plot of SARS-CoV 3CLpro 3D structure and ligand surrounding amino acids are presented in Fig 4c \& 4f. Like SARS-CoV2, five amino acid residues- Gly-92, -143, -183, -215, and -275 were found to be distributed in disallowed region of the plot. Most of the amino acids surrounding eltrombopag are found to be in favorable regions forming $\beta$-sheets and $\alpha$-helix (Fig 4f).
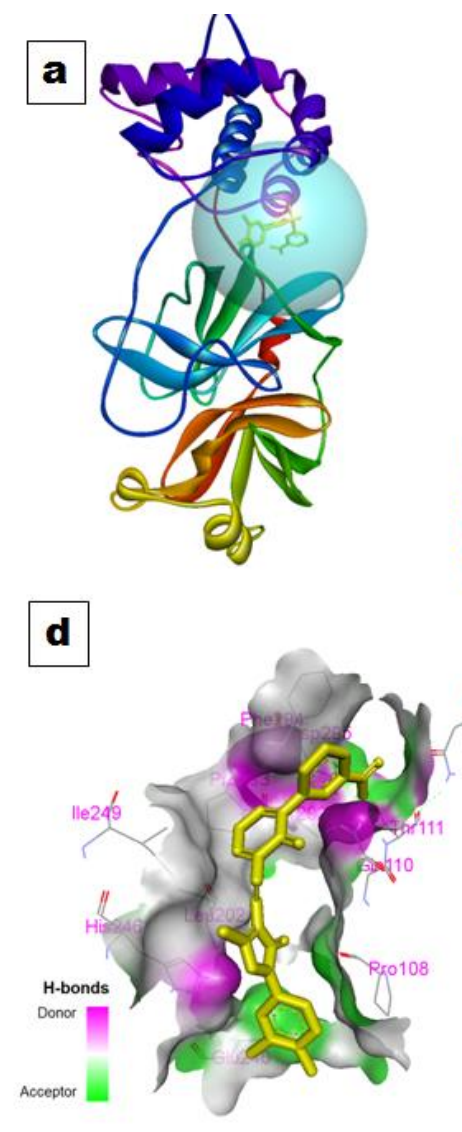
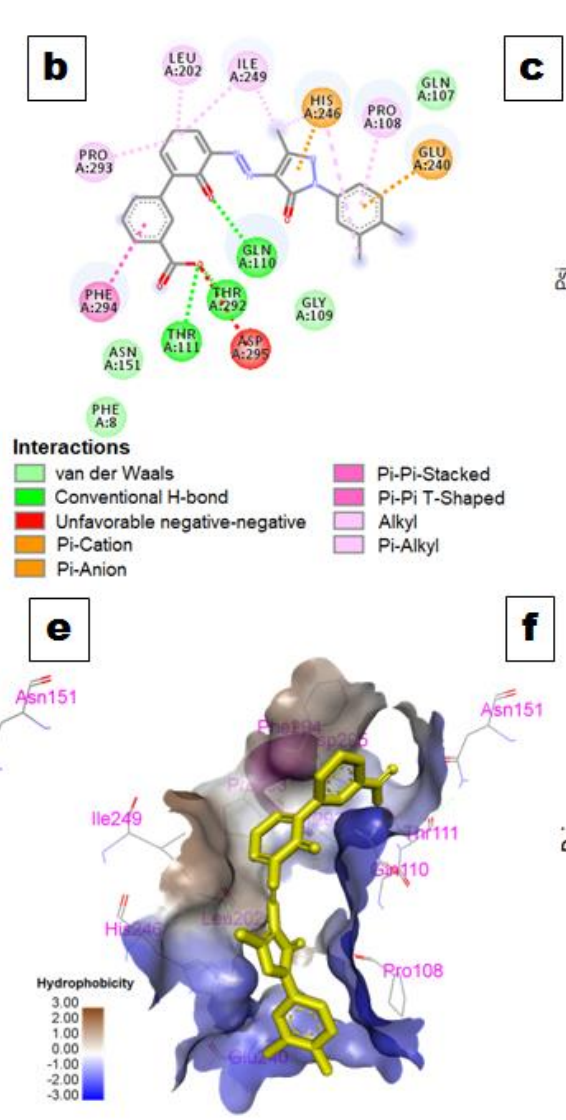
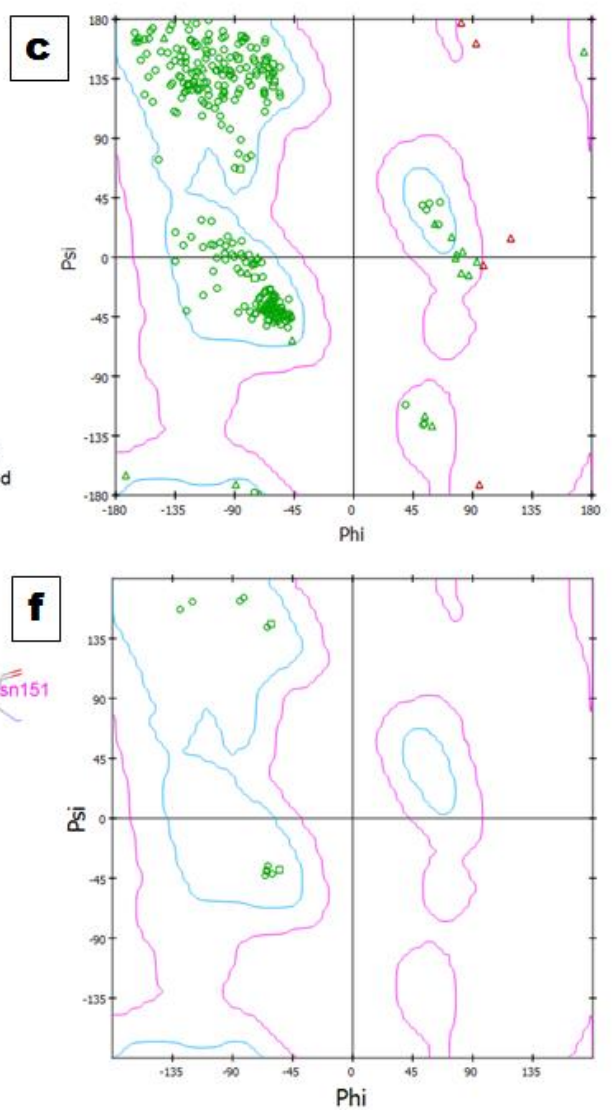

Fig. 4 Binding interactions of SARS-CoV 3CLpro and eltrombopag. (a) Ligand binding sphere view, (b) 2D display of eltrombopag-3CLpro interactions, (c) Ramachandran plot of 3CLpro, (d) H-bond property of binding pocket, (e) Hydrophobicity profile of binding pocket, and (f) Ramachandran plot of eltrombopag interacting amino acid residues.

Similarly, Fig. 5 and 6 showed the binding affinity, hydrophobicity, and Ramachandran plot profile of PLpro enzyme of SARS-CoV2 and SARS-CoV, respectively. It is seen from the ligand-binding site sphere views of PLpro that the two CoVs have marked differences in terms of its binding sites (Fig 5a \& 6a). The best binding drug eltrombopag is found to make interactions with 13 and 11 amino acids surrounding the active pocket of the PLpro enzymes of SARS-CoV2 and SARS-CoV, respectively. Out of the 13 and 11 surrounding amino acids of PLpro, 


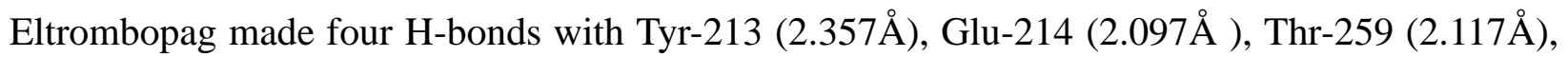

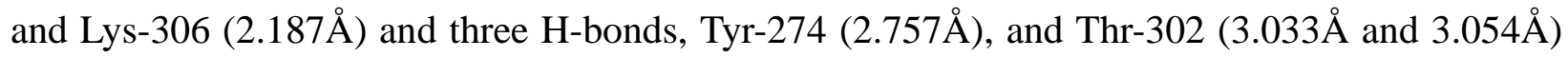
of SARS-CoV2 and SARS-CoV, respectively (Fig $5 \mathrm{~b}$ and $6 \mathrm{~b}$ ). In addition to H-bond, several other non-covalent interactions such as Van der Waals, Pi-bond, Pi-alkyl, and alkyl bonds were also observed between ligand and the protein. Fig 5d and 6d represent the HBD and HBA amino acids of the ligand surrounding residues of PLpro enzyme. Ramachandran plots showed that a total of 8 and 7 amino acid residues (all glycine) are distributed outside the allowed region in PLpro of SARS-CoV2 and SARS-CoV, respectively (Fig 5c \& 6c). Hydrophobicity display showed that 12 out of 13 amino acid residues surrounding the ligand are found to be hydrophilic in nature while all the 11 residues are hydrophilic in the PLpro of SARS-CoV2 and -CoV, respectively (Fig 5e \& 6e). Similarly, Fig. $5 \mathrm{f}$ and $6 \mathrm{f}$ displayed the distribution of PLpro ligandbinding residues in the Ramachandran plots.
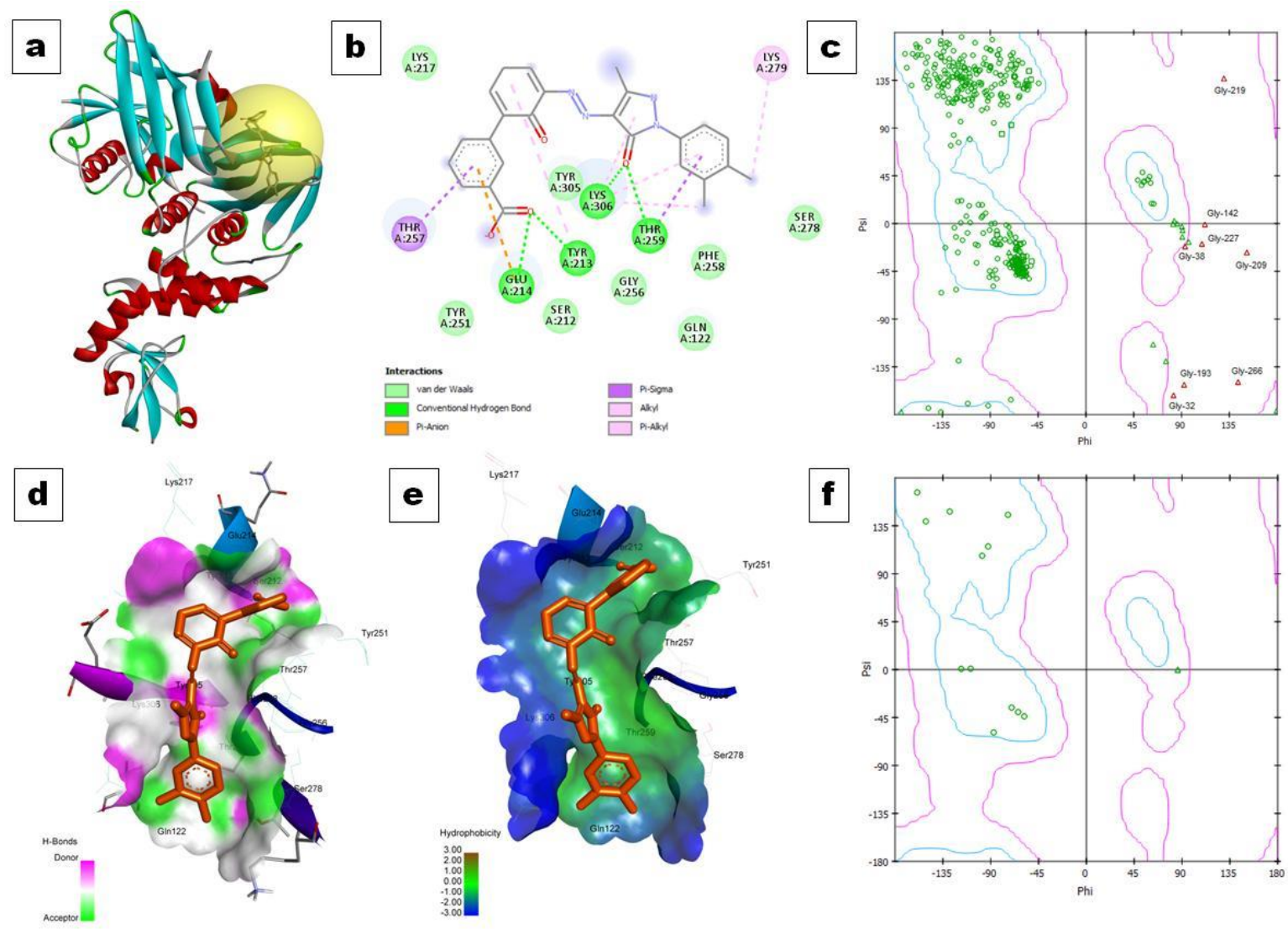

Fig. 5 Binding interaction of SARS-CoV2 PLpro and Eltrombopag (a) Ligand binding sphere view, (b) 2D display of Simeprevir-PLpro interactions, (c) Ramachandran plot of PLpro, (d) H-bond property of binding pocket, (e) Hydrophobicity profile of binding pocket, and (f) Ramachandran plot of eltrombopag interacting amino acid residues. 

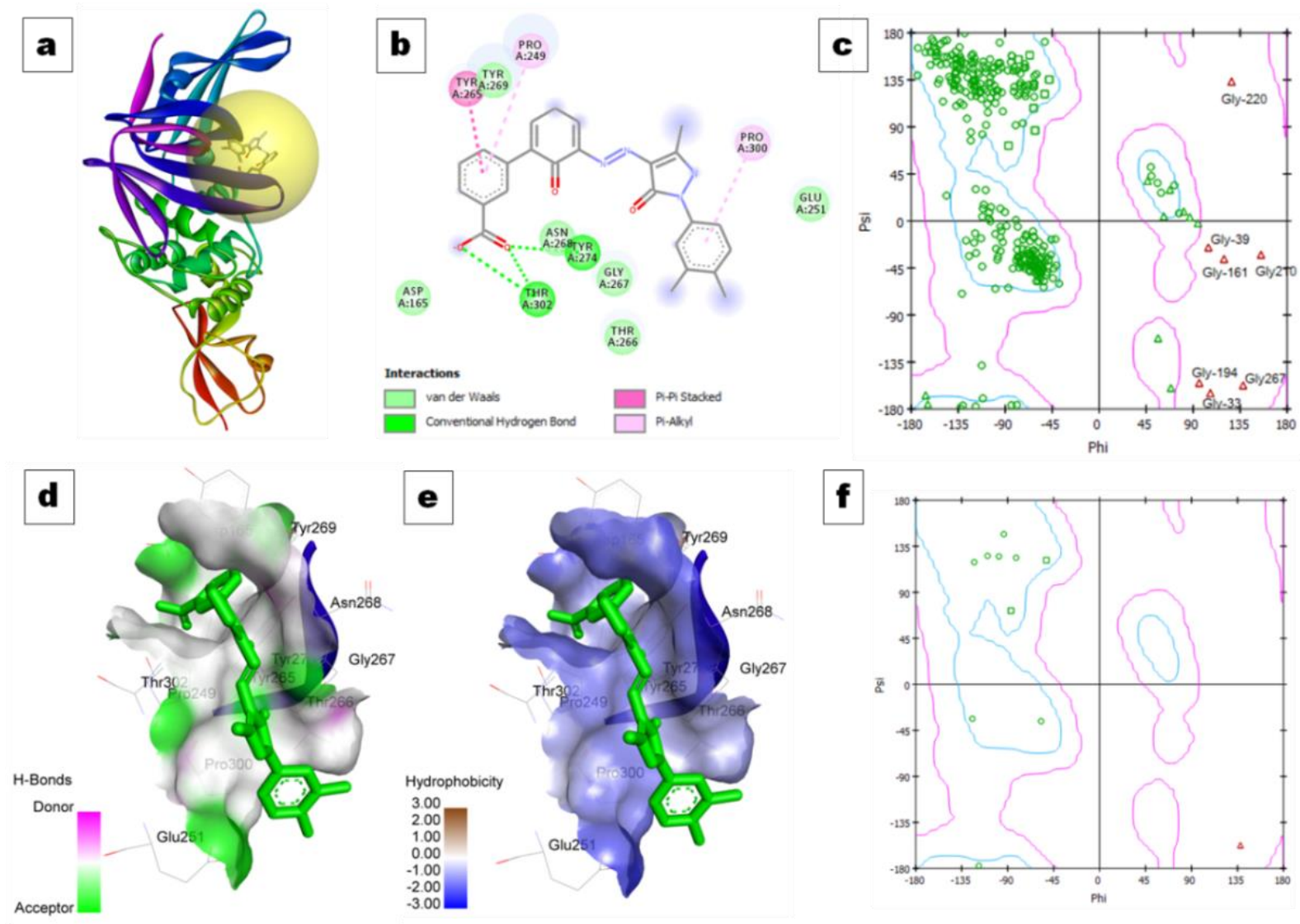

Fig. 6 Binding interaction of SARS-CoV PLpro and Eltrombopag (a) Ligand binding sphere view, (b) 2D display of Simeprevir-PLpro interactions, (c) Ramachandran plot of PLpro, (d) H-bond property of binding pocket, (e) Hydrophobicity profile of binding pocket, and (f) Ramachandran plot of eltrombopaginteracting amino acid residues.

\subsection{Validation based on machine learning algorithms}

The Assay Central Bayesian model for SARS CoV 3CLpro enzyme has a 5-fold cross-validation receiver operating characteristic (ROC) of 0.92 , precision 0.85 , recall 0.98 , specificity $0.78, \mathrm{~F} 1$ score 0.91, Cohen's kappa (CK) 0.78, and Matthews correlation coefficient (MCC) 0.78 (Fig. 7a). For SARS-CoV 3CLpro, prediction score (Pm) and applicability score (AS) of potent drug eltrombopag was 1.10 and 0.76 respectively (Fig. 8b). In contrast, the SARS CoV PL protease enzyme has a 5-fold cross-validation receiver operating characteristic (ROC) of 0.71 , precision 0.40, recall 0.63, specificity 0.75, F1-score 0.49, Cohen's kappa (CK) 0.31, and Matthews correlation coefficient (MCC) 0.33 (Fig. 7b). For SARS-CoV PL protease, prediction score (Pm) and applicability score (AS) of potent drug eltrombopag was 0.49 and 0.76 respectively (Fig. 8b). Furthermore, for coronavirus disease (COVID-19) associated SARS-CoV2 3C like protease enzyme has a 5-fold cross-validation receiver operating characteristic (ROC) of 0.94 , precision 0.43 , recall 0.93 , specificity 0.82 , F1 score 0.59 , Cohen's kappa (CK) 0.50 and Matthews correlation coefficient (MCC): 0.56 (Fig. 8a). For SARS-CoV2 3CL protease, the prediction 
score (Pm) and applicability score (AS) of potent drug, simeprevir was 1.03 and 0.65 (Fig. 8b). Unfortunately, for SARS-CoV2 PL-protease; no data was available in the assay central database and hence, could not be validated by the same method.

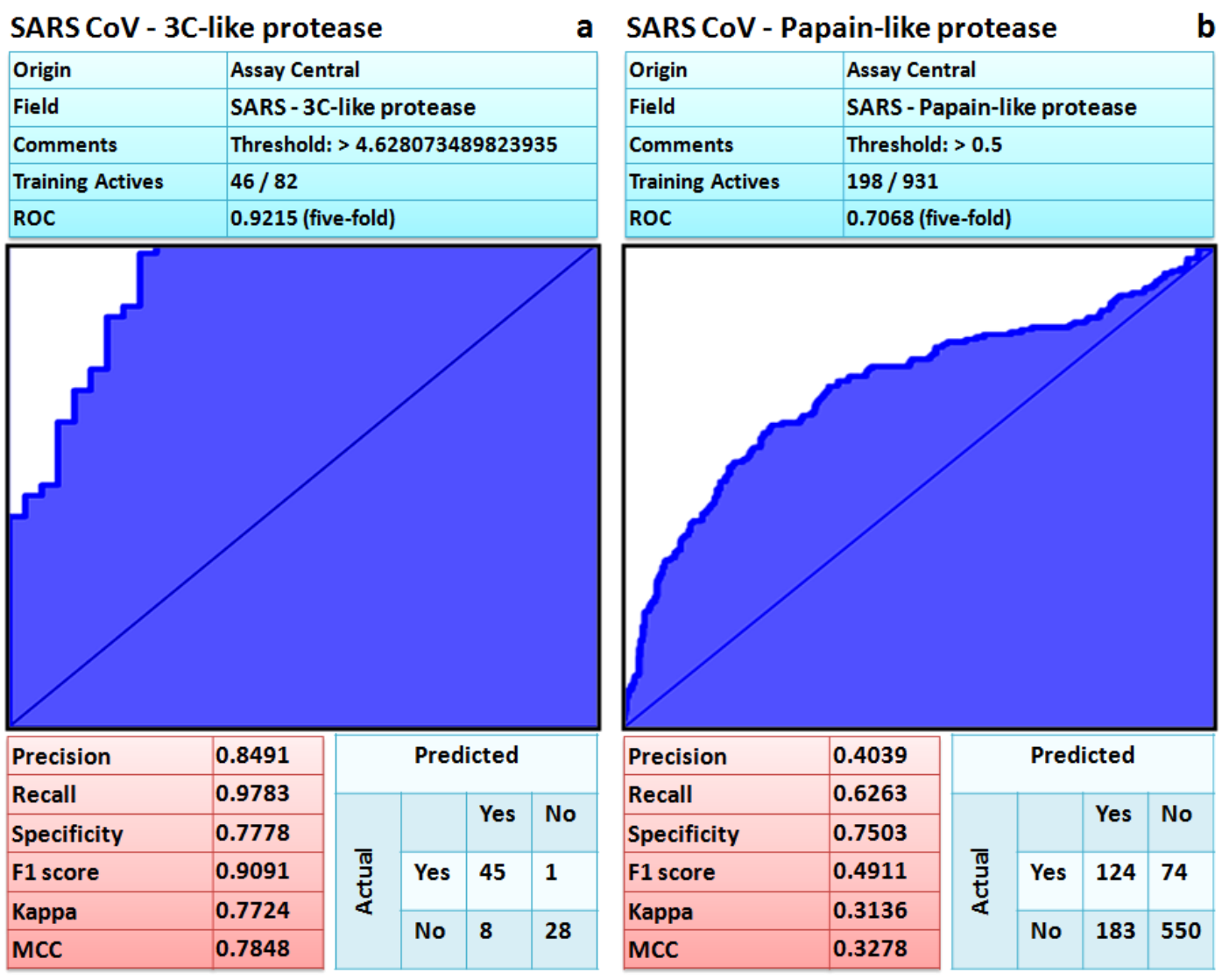

Fig. 7 Assay central visualization. Machine learning model performance summary of a Bayesian algorithm. Bayesian machine learning models using ECFP6 fingerprints were used for scoring and selecting compounds to predict potent binding affinity with SARS CoV 3CL pro (a) and SARS CoV 3PL ${ }^{\text {pro }}$ (b) proteins. 


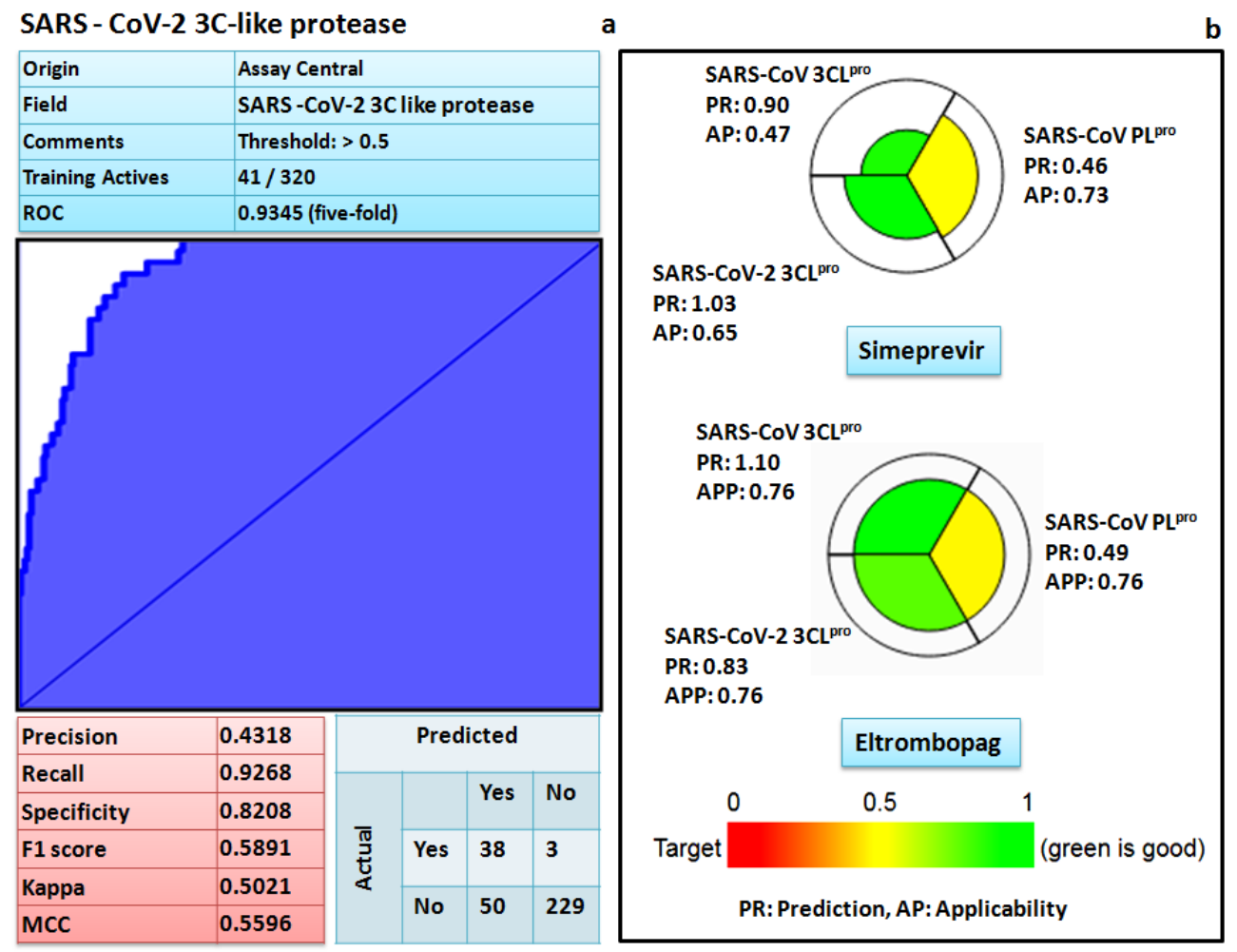

Fig. 8 Assay Central Visualization. (a) Machine learning model performance summary of a Bayesian algorithms. Bayesian machine learning models using ECFP6 fingerprints were used for scoring and selecting compounds to predict potent binding affinity with target proteins and (b) Prediction and applicability score of potent compounds simeprevir and eltrombopag against different target proteins.

\subsection{ADMET study}

The heat map of ADMET properties of all the top ten best-binding drugs with 3CLpro and PLpro is presented in Fig 9. It is observed that all the drugs have high tendency of being absorbed by human intestine except few drugs such as lopinavir, anidulafungin which showed weaker absorption property by the human intestine. Best docking ligand, simeprevir and eltrombopag were predicted to have high absorption property. All the top protease-binding drugs were found to have high permeability property through blood brain barrier (BBB) except, ciclesonide and camostat. Cytochrome-P450 (CYP) enzyme super family is a group of enzymes that metabolize xenobiotic substances that come inside the body. Many drugs are known to increase or decrease the activity of various CYP-isozymes. CYP3A4 (EC 1.14. 13.97), one of the major enzyme of drug metabolism is found to be inhibited by almost all the drugs. The drugs are predicted to act as a strong substrate and thus bind at the active site of the enzyme and inhibit the enzyme function. Inhibition of CYP3A4 enzyme therefore cannot metabolize the drugs. Similarly, the half life and clearance rate of all the drugs are found to be low. The drugs, on the contrary showed potential candidate for hERG (human Ether-a-go-go-Related Gene) inhibitor thus may 
cause side effect such as electrical activity in heart. The drugs also showed hepatotoxicity and liver injury in host body.

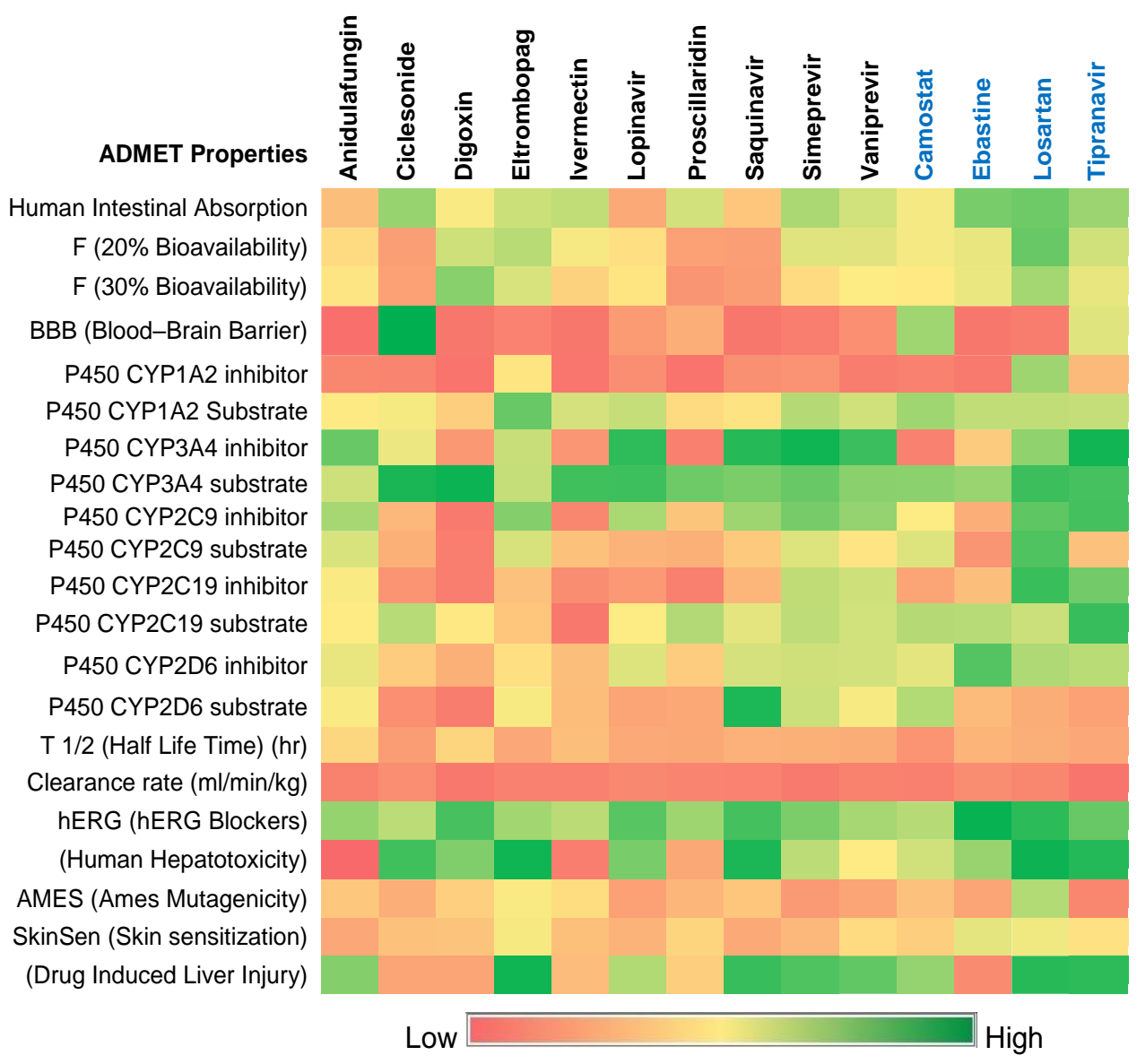

Fig. 9 ADMET properties of top ten drugs binding with 3CLpro and PLpro proteins of SARS-CoV2 and SARS-CoV. All the top 10 ligands share strongest binding affinity both in 3CLpro and PLpro, except four (blue color font) that binds strongly with PLpro.

\section{Discussion}

COVID-19 and its causative organism SARS-CoV2 have caused havoc all across the globe and yet the world is far from approved therapeutic agent(s). Millions of lives have lost so far and the future is still cloudy, and therefore, the current situation demands speedy approval of drugs or vaccines to combat this dreadful virus. Laboratory-based in-vitro and in-vivo studies are tedious, costly, and most importantly, a time-consuming process. As an alternative, repurposing of existing drugs and computer-aided drug screening can accelerate the drug development process (Ashburn and Thor 2004). Several recent studies have investigated the existing antiviral and other miscellaneous drugs to see whether these drugs have any role against SARS-CoV2 (Colson et al., 2020; Kandeel and Al-Nazawi, 2020; Swargiary, 2020). Two important therapeutic drug 
targets of coronaviruses, 3-chymotrypsin-like protease, and papain-like protease have been investigated by many researchers to find out candidate $\operatorname{drug}(\mathrm{s})$ that inhibit the functioning of these proteases (Elmezayen et al., 2020; Wang et al., 2020). The present study found that simeprevir, a known Hepatitis C virus NS3/4A protease inhibitor, binds to the active site of 3CLpro much stronger than other drugs. Similarly, Hosseini and Amanlou (2020) also found that simeprevir fit well into the active site of main protease enzyme. In vitro and biochemical characterization studies by Lo et al. (2020) revealed that simeprevir is a potential drug for treating COVID-19. In another study, Mahdian et al. (2020) showed the strong binding affinity of simeprevir with different proteins of coronaviruses suggesting potential drug candidates for candidates to treat COVID-19 infections. Furthermore, simeprevir is also found to bind strongly with papain-like protease. Eltrombopag, an FDA approved drug used to treat low blood platelet count showed strongest binding affinity to PLpro enzyme suggesting potential inhibitor of the enzyme. Similar to the present finding, Gul et al. (2020) also reported strong binding affinity of eltrombopag with 3CLpro and RdRp enzyme. Like many other studies, we also found strong binding affinity of ivermectin, an antihelmintic drug, with both the protease enzymes of SARS$\mathrm{CoV}$ and-CoV-2. In a recent in-vitro study, Caly et al. (2020) reported ivermectin as a potent inhibitor of SARS-CoV2 replication. Patri and Fabbrocini (2020) also believe that use of ivermectin in combination with hydroxychloroquine can help in the treatment of COVID-19. In a recent in-silico study ivermectin has been shown as a promising $\mathrm{RdRp}$ inhibitor and possible therapeutic drug against COVID-19 (Swargiary, 2020). Our study, however, showed weaker binding interaction of hydroxychloroquine with 3CLpro and PLpro of both the coronaviruses. Remdesivir and hydroxychloroquine showed more or less similar binding affinities to protease enzymes. Preliminary studies have observed that the use of remdesivir shorten the time of recovery, and lowers the respiratory tract infection (Beigel et al., 2020).

Assay Central is a stand-alone set of predictive Bayesian and Random Forest models for non-experts to determine the likelihood of action of bioactive compounds against target of interest. After developing the model, each molecule in the selected 'project' receives a relative score, applicability number (fraction of structural features shared with the training set) (Clark et al., 2015). In general, the prediction score ranges from 0-1; a higher score means the compound is more likely to be active at the modeled target. The current threshold for considering a compound as active is a score of 0.5 or higher. In addition, the applicability score refers to the percent of fragments from the predicted molecule that are present in the model. Lesser score suggests that the prediction is not as effective, because the molecules comprising the model do not contain a large portion of the predicted compound. The attribute of the ROC or the receiver operator can be interpreted as a percent probability of correctly predicting compound activity against target. Additional metrics include F1 Score, Cohen's Kappa, and Matthew's Correlation Constant (MCC) and these statistical parameters ranges from 0-1, and the closer to 1 the more predictive the model is considered to be good (Clark et al., 2015; Krems, 2019). Thus, based on the machine learning algorithm it can be suggested that aforesaid drug candidates such as 
simeprevir and eltrombopag possess strong binding affinity against SARS associated target proteins and hence showing high prediction and applicability scores.

In-silico druglikeness and ADMET properties are important parameters for the screening of the possible drug candidate. By using in-silico tools it is now possible to predict the druglikeness of a compound based on its structure, physical, and chemical properties (Dimasi et al., 2003; Swargiary et al., 2020). A good drug candidate must have high absorption property by the intestinal cell, must distribute easily to the cells without being metabolized en route, must have a high elimination rate, and less toxic effect to the body (Dong et al., 2018; Guan et al., 2019). All the top protease binding ligands including simeprevir and eltrombopag showed high absorption property by the cells. Cytochrome-P450 (CYP) super family of enzymes is an enzyme complex involved in the metabolism of xenobiots inside the body (Nelson et al., 2004). Metabolism of oral drug by CYP-enzyme super family en route before reaching the target site decreases the effectiveness of any drug. Furthermore, some drugs inhibit those metabolizing enzyme and therefore are not metabolized en route reaching the target site showing high efficacy. In many cases, the drugs may become substrate to the CYP-enzyme complex and are used by the enzymes before reaching the target site (Lunch and Price, 2007). Simeprevir is found to possess inhibitory property against several CYP-super family enzymes which suggest the possibility of reaching to the target sites. Eltrombopag, on the other hand showed moderate to high inhibitory property of certain CYP-super family enzymes while in others it acts as a substrate. Similarly, all the top binding ligands of 3CLpro and PLpro showed low to high inhibitory property to certain CYP-super family enzymes suggesting its high possibility to reach the target site. The FDA approved drugs of present study also found to possess moderate to high toxicity effects in the host body. The present study thus suggests that the FDA approved drug simeprevir, along with eltrombopage, digoxin, and tipranavir may act as a strong inhibitor to 3CLpro and PLpro and therefore, may be a promising drug to combat SARS-CoV2 and COVID19.

\section{Conclusion}

The present study highlights the binding affinities of 61 drugs against two key SARS-CoV2 proteases, 3 chymotrypsin-like and Papain-like proteases. The study revealed that out of 61 drugs simeprevir and eltrombopag have the strongest binding affinity to 3CLpro and PLpro active sites and therefore inhibit the function of both the proteases. All the known protease inhibitors including saquinavir, vaniprevir, lopinavir, danoprevir, and nelfinavir also showed high affinity for both the protease enzymes. Furthermore, other non-antiviral drugs such as digoxin, ivermectin, camostat, ebastine, penfluridole, and abemaciclib also showed strong binding affinity to both the enzymes. The Assay Central Bayesian models further corroborate the finding of molecular docking and ranked simeprevir and eltrombopag as possible lead molecules among others for future validation. The present study thus suggest that the along with known antiviral drugs researchers can also focus on unknown antiviral drugs which may prove effective in combating COVID-19. 


\section{Funding}

There is no funding for the current study

\section{Acknowledgement}

Authors acknowledge the Head, department of Zoology, Bodoland University for providing necessary facility to carry out this work.

\section{Conflict of interest}

Authors do not have any conflict of interest.

\section{References}

Angela P, Fabbrocini G (2020) Hydroxychloroquine and ivermectin: A synergistic combination for COVID-19 chemoprophylaxis and treatment? Journal of the American Academy of Dermatology 82(6): e221. DOI: 10.1016/j.jaad.2020.04.017

Ashburn TT, Thor KB (2004) Drug repositioning: identifying and developing new uses for existing drugs. Nature Reviews Drug Discovery 3(8), 673-683. OI: 10.1038/nrd1468

Beigel J, Tomashek KM, Dodd L, Mehta AK, Zingman BS, et al. (2020) Remdesivir for the treatment of Covid-19: Preliminary report. The New England Journal of Medicine. DOI: 10.1056/NEJMoa2007764

Benvenuto D, Giovanetti M, Ciccozzi A, Spoto S, Angeletti S, Ciccozzi M (2020) The 2019-new coronavirus epidemic: Evidence for virus evolution. Journal of medical Virology 92(4): 455-459. https://doi.org/10.1002/jmv.25688

Bhattacharyya MK, Dutta D, Nashre-ul-Islam SM, Frontera A, Sharma P, Verma AK, et al. (2019) Energetically Significant antiparallel $\pi$-stacking contacts in $\mathrm{Co}(\mathrm{II}), \mathrm{Ni}$ (II) and $\mathrm{Cu}$ (II) coordination compounds of pyridine-2,6-dicarboxylates: Antiproliferative evaluation and theoretical studies. Inorganica Chimica Acta 501: 11923. https://doi.org/10.1016/j.ica.2019.119233

Caly L, Druce JD, Catton MG, Jans DA, Wagstaff KM (2020) The FDA-approved drug ivermectin inhibits the replication of SARS-CoV2 in vitro. Antiviral Research 178: 104787. doi:10.1016/j.antiviral.2020.104787

Clark AM, Dole K, Coulon-Spektor A, McNutt A, Grass G, Freundlich JS, et al. (2015) Open source Bayesian models. 1. Application to ADME/Tox and drug discovery datasets. Journal of Chemical Information and Modeling 55(6): 1231-1245. DOI: 10.1021/acs.jcim.5b00143

Clercq D, Li G (2016) Approved antiviral drugs over the past 50 years. Clinical Microbiology Review 29: 695-747. doi:10.1128/CMR.00102-15 
Colson P, Rolain J, Lagier J, Brouqui P, Raoult D (2020) Chloroquine and hydroxychloroquine as available weapons to fight COVID-19. International Journal of Antimicrobial Agents 55(4). https://doi.org/10.1016/j.ijantimicag.2020.105932

Cui J, Li F, Shi Z (2019) Origin and evolution of pathogenic coronaviruses. Nature Reviews Microbiology 17: 181-192. https://doi.org/10.1038/s41579-018-0118-9

Dai W, Zhang B, Jiang X, Su H, Li J, Zhao Y, et al. (2020) Structure-based design of antiviral drug candidates targeting the SARS-CoV2 main protease. Science 368: 1331-1335. DOI: 10.1126/science.abb4489

Daina A, Michielin O, Zoeteb V (2017) SwissADME: a free web tool to evaluate pharmacokinetics, drug-likeness and medicinal chemistry friendliness of small molecules. Scientific Reports 7: 42717. https://doi.org/10.1038/srep42717

DiMasi JA, Hansen RG, Grabowski HG (2003) The price of innovation: new estimates of drug development costs. J. Health Econ 22: 151-185. doi:10.1016/S0167-6296(02)00126-1

Dong J, Wang N, Yao Z, Zhang L, Cheng Y, Ouyang D, et al. (2018) ADMETlab: a platform for systematic ADMET evaluation based on a comprehensively collected ADMET database. $\mathrm{J}$ Cheminformatics 10: 29. http://doi: 10.1155/2012/281078

Elmezayen A, Al-Obaidi A, Sahin A, Yelekci K (2020) Drug repurposing for coronavirus (COVID-19): In-silico screening of known drugs against coronavirus 3CL hydrolase and protease enzymes. Journal of Biomolecular Structure and Dynamics. DOI: 10.1080/07391102.2020.1758791

Forni D, Cagliani R, Clerici M, Sironi M (2017) Molecular evolution of human coronavirus genomes. Trends in Microbiology 25: 35-48. https://doi.org/10.1016/j.tim.2016.09.001

Gandhi RT, Lynch JB, Rio C (2020) Mild or Moderate Covid-19. New England Journal of Medicine. https://doi.org/10.1056/NEJMcp2009249

Guan L, Yang H, Cai Y, Sun L, Di P, Li W, et al. (2019) ADMET-score - a comprehensive scoring function for evaluation of chemical drug-likeness. MedChemComm 10: 148-157. https://doi.org/10.1039/C8MD00472B

Gul S, Ozcan O, Asar S, Okyar A, Barıs I, Kavakli IH (2020) In-silico identification of widely used and well-tolerated drugs as potential SARS-CoV2 3C-like protease and viral RNAdependent RNA polymerase inhibitors for direct use in clinical trials. Journal of Biomolecular Structure and Dynamics. DOI: 10.1080/07391102.2020.1802346

Hilgenfeld R (2014) From SARS to MERS: crystallographic studies on coronaviral proteases enable antiviral drug design. FEBS Journal 281(2014): 4085-4096. doi:10.1111/febs.12936

Hosseini FS, Amanlou, M (2020) Simeprevir, potential candidate to repurpose for coronavirus infection: virtual screening and molecular docking study. Life Sciences 258: 2020. https://doi.org/10.1016/j.lfs.2020.118205

Huang SY, Zou X (2010) Advances and challenges in protein-ligand docking. International Journal of Molecular Sciences 11(8): 3016-3034. doi: 10.3390/ijms11083016 
Jeon S, Ko M, Lee J, Choi I, Byun SY, Park S, Shum D, Kim S (2020) Identification of antiviral drug candidates against SARS-CoV2 from FDA-approved drugs. Antimicrobial Agents and Chemotherapy 64: e00819-20. https://doi.org/10.1128/AAC.00819-20

Kandeel M, Al-Nazawi M (2020) Virtual screening and repurposing of FDA approved drugs against COVID-19 main protease. Life Sciences 251: 2020. https://doi.org/10.1016/j.lfs.2020.117627

Krems RV (2019) Bayesian machine learning for quantum molecular dynamics. Physical Chemistry Chemical Physics, 21(25): 13392-13410

Li H, Zhou Y, Zhang M, Wang H, Zhao Q, Liu J (2020) Updated approaches against SARSCoV2. Antimicrobial Agents and Chemotherapy 64:e00483-20. https://doi.org/10.1128/AAC .00483-20

Lo H, Hui K, Lai H, Khan KS, Kaur S, Li Z, et al. (2020) Simeprevir suppresses SARS-CoV2 replication and synergizes with remdesivir. BioRxiv 2020.05.26.116020. https://doi.org/10.1101/2020.05.26.116020

Lynch T, Price A (2007) The effect of cytochrome P450 metabolism on drug response, interactions, and adverse effects. American Family Physician 76(3): 391-396.

Macchiagodena M, Pagliai M, Procacci P (2020) Identification of potential binders of the main protease 3CLpro of the COVID-19 via structure-based ligand design and molecular $\begin{array}{lllll}\text { modeling. } & \text { Chemical } & \text { Physics } & \text { Letters } & 750 \text { : }\end{array}$ https://doi.org/10.1016/j.cplett.2020.137489

Mahdian S, Ebrahim-Habibi A, Zarrabi M (2020) Drug repurposing using computational methods to identify therapeutic options for COVID-19. Journal of Diabetes \& Metabolic Disorders. https://doi.org/10.1007/s40200-020-00546-9

Ma-Lauer Y, Carbajo-Lozoya J, Hein MY, Müller MA, Deng W, Jian Lei, et al. (2016) p53 down-regulates SARS coronavirus replication and is targeted by the SARS-unique domain and PLpro via E3 ubiquitin ligase RCHY1. Proceedings of the National Academy of Sciences of the United States of America 113(35): E5192-E5201. https://doi.org/10.1073/pnas.1603435113

McKee D, Sternberg A, Stange U, Laufer S, Naujokat C (2020) Candidate drugs against SARSCoV2 and COVID-19. Pharmacological Research 157: 1043-6618. https://doi.org/10.1016/j.phrs.2020.104859

Morse JS, Lalonde T, Xu S, Liu WR (2020) Learning from the past: Possible urgent prevention and treatment options for severe acute respiratory infections caused by 2019-nCoV. ChemBioChem 21(5): 730-738. https://doi.org/10.1002/cbic.202000047

Nelson DR, Zeldin DC, Hoffman SM, Maltais LJ, Wain HM, Nebert DW (2004) Comparison of cytochrome P450 (CYP) genes from the mouse and human genomes, including nomenclature recommendations for genes, pseudogenes and alternative-splice variants. Pharmacogenetics 14 (1): 1-18. 
Pettersen EF, Goddard TD, Huang CC, Couch GS, Greenblatt DM, Meng EC, Ferrin TE (2004) UCSF Chimera--a visualization system for exploratory research and analysis. Journal of Computational Chemistry 25(13): 1605-1612. Doi: 10.1002/jcc.20084

Shin D, Mukherjee R, Grewe D, Bojkova D, Baek K, et al. (2020) Papain-like protease regulates SARS-CoV2 viral spread and innate immunity. Nature 2020. Doi:10.1038/s41586-0202601-5

Su S, Wong G, Shi W, Liu J, Lai ACK, Zhou J (2016) Epidemiology, genetic recombination, and pathogenesis of coronaviruses. Trends in Microbiology 24: 490-502. https://doi.org/10.1016/j.tim.2016.03.003

Swargiary A (2020) Ivermectin as a promising RNA-dependent RNA polymerase inhibitor and a therapeutic drug against SARS-CoV2: Evidence from in silico studies. Research Square, Preprint. DOI: 10.21203/rs.3.rs-54096/v1

Swargiary A, Verma AK, Singh S, Roy MK, Daimari D (2020) Antioxidant and antiproliferative activity of selected medicinal plants of lower Assam, India: An in vitro and in silico study. Anti-cancer Agent in Medicinal Chemistry (E-pub ahead of print). DOI: 10.2174/1871520620666200719000449

Trott O, Olson AJ (2010) AutoDock Vina: improving the speed and accuracy of docking with a new scoring function, efficient optimization and multithreading. Journal of Computational Chemistry 31(2): 455-461. http://doi: 10.1002/jcc.21334

Wang J (2020) Fast identification of possible drug treatment of coronavirus disease-19 (COVID19) through computational drug repurposing study. Journal of Chemical Information and Modeling 60(6): 3277-3286. DOI: 10.1021/acs.jcim.0c00179

WHO (2020). https://www.who.int/emergencies/diseases/novel-coronavirus-2019. Retrieved on 11-08-2020

Wu A, Peng Y, Huang H, Ding X, Wang X, Niu P, et al. (2020). Genome composition and divergence of the novel coronavirus (2019-nCoV) originating in China. Cell Host \& Microbe 27(3): 325-328. https://doi.org/10.1016/j.chom.2020.02.001

Wu C, Liu Y, Yang Y, Zhang P, Zhong W, Wang Y, et al. (2020) Analysis of therapeutic targets for SARS-CoV2 and discovery of potential drugs by computational methods. Acta Pharmaceutica Sinica B 10(5): 766-788. https://doi.org/10.1016/j.apsb.2020.02.008

Zhou H, Fang Y, Xu T, Ni WJ, Shen AZ, Meng XM (2020) Potential therapeutic targets and promising drugs for combating SARS-CoV-2. British Journal of Pharmacology 177: 31473161. https://doi.org/10.1111/bph.15092

Zhou J, Fang L, Yang Z, Xu S, Lv M, Sun Z, et al. (2019). Identification of novel proteolytically inactive mutations in coronavirus $3 \mathrm{C}$-like protease using a combined approach. The FASEB Journal 33(12): 14575-14587. https://doi.org/10.1096/fj.201901624RR 